\title{
Job embeddedness, organisational commitment and voluntary turnover of academic staff at a higher education institution in South Africa
}

\author{
by Cebile Mensele* and Melinde Coetzee
}

\begin{abstract}
Academic staff recruitment and retention remain a challenge in South Africa and internationally. Most academics at South African universities are ageing, with fewer younger people entering academia. The objectives of the study were to determine empirically whether job embeddedness and organisational commitment significantly predict voluntary turnover and whether people from different gender, race and age groups differ significantly in terms of these three variables. The measuring instruments used were the Job Embeddedness Scale (JES), the Organisational Commitment Scale (OCS) and the Voluntary Turnover Scale (VTS). A cross-sectional quantitative survey design was used to collect data from a random sample of $(N=102)$ full-time academic staff at a South African higher education institution in Gauteng. The findings showed that organisational fit, community links and normative commitment significantly and positively predicted the participants' intention to stay at the institution. Female participants showed higher levels of organisational fit and sacrifice, hence a stronger intention to stay. White participants had stronger community links and fit, and the African participants had higher levels of normative commitment than the other race groups. The current study adds to the knowledge base on the turnover intentions of academic staff and makes recommendations for retention practices and possible future research.
\end{abstract}

Key words: job embeddedness, organisational commitment, voluntary turnover, intention to stay, academic staff, staff retention

\section{Introduction}

The increasingly volatile economy, persistent employee movement to other organisations and the cost involved in voluntary turnover are important concerns for managers (Heymann 2010; Holtom \& Inderrieden 2006; Mitchell, Holtom \& Lee 2001b; Pillay 2009; Weibo, Kaur \& Zhi 2010). Higher education institutions have faced numerous changes in the last two decades, with these changes posing varying challenges to an already strained higher education system (Rothman \& Jordaan 2006). Tettey (2010) highlights the challenges faced by academic staff at universities: Student: staff ratios have doubled, with the ratio currently standing at 39:1, while academic staff recruitment and retention remain a challenge in South Africa and across the globe

\footnotetext{
Mrs C Mensele is a lecturer in the Department of Industrial and Organisational Psychology at the University of South Africa.

"* Prof M Coetzee is a professor in the Department of Industrial and Organisational Psychology at the University of South Africa.
} 
(Pienaar \& Bester 2006). Tettey (2010) and Sutherland and Jordaan (2004) assert that the majority of lecturing staff at South African universities are ageing, with fewer younger people entering academia. Martin and Roodt (2008) posit that there is a need for further studies at higher education institutions to establish the turnover behaviour of academic staff.

Studies that have investigated employee turnover have focused on attitudes or components of turnover, including organisational commitment and lower levels of job satisfaction (Harman, Lee, Mitchell, Felps \& Ownes 2007; Mitchell, Holtom, Lee, Sablynski \& Erez 2001). Organisational commitment is seen as a work-related attitude that refers to a state in which an employee identifies with the organisation and its goals, and intends to remain a member of the organisation (Meyer \& Allen 1991, Robbins, Odendaal \& Roodt, 2003; Slocum \& Hellriegel 2007). Individuals who are high on organisational commitment show support for and acceptance of the organisation's goals and values, a willingness to go beyond the call of duty and a wish to remain in the organisation (Slocum \& Hellriegel 2007).

According to Mitchell, Holtom and Lee (2001), employees could leave for personal or organisational reasons, or even both. These authors cite changes in the family situation, a desire to upskill or unsolicited job offers as some of the personal reasons that could lead to an employee's leaving the organisation. Organisational reasons that could result in an employee voluntarily leaving include unfair treatment of other employees, being passed over for promotion or being asked to do something that is contrary to the person's values or beliefs.

Firth, Mellor, Moore and Loquet (2003) criticise traditional studies of turnover because they have yielded little consistency in investigating intentions to leave, possibly on account of the diversity of constructs included and the lack of consistency in the measurements used. Mitchell et al (2001a) argue that studies have indicated attitudinal variables as controlling only about 4 to $5 \%$ of the variance in turnover hence the need to consider the reasons for people staying and how organisations can retain their staff.

In view of the concerns for establishing why employees retain their citizenship in the organisation instead of leaving, the construct "job embeddedness" was coined (Mitchell et al 2001a; Mitchell et al 2001b). Mitchell et al (2001b) emphasise that people who leave are relatively satisfied with their jobs and were not searching for other jobs before leaving. Their leaving the organisation is more likely to be an unplanned event than the result of a negative attitude towards their job or the organisation. Job embeddedness therefore emphasises that it is not only job-related factors that could influence an individual's decision to stay with the organisation - the community could also play a role. Job embeddedness is essentially the force that binds employees to their current jobs and organisations as a result of their relationships with people and activities in the web (Lim \& Wong 2009; Mitchell et al 2001a).

In South Africa, there is a paucity of studies investigating job embeddedness in relation to voluntary turnover. Pillay (2009) investigated mission attachment as a component of organisational embeddedness in the trade union sector. One of the conclusions of this study was that age influences the level of attachment - hence the employees' organisational/job embeddedness. Heymann (2010) found that demographic factors such as age, gender and race influenced job embeddedness and voluntary turnover of employees with specialised knowledge and skills.

Organisational commitment is similar to job embeddedness in some instances, but there are also notable differences between the two variables. Organisational 
commitment focuses on feelings that foster continued citizenship in the organisation and assesses on-the-job dimensions, whereas job embeddedness incorporates factors both on and off the job and its dimensions are nonaffective (Mitchell et al 2001a). According to Harman et al (2007), traditional research on turnover has maintained that employees leave organisations as a result of negative job attitudes and stay because of positive job attitudes. Job embeddedness attempts, firstly, to expand the scope of variables that may be used to understand why employees stay by including factors that are nonaffective (structural links to other people), and secondly, to consider off-the-job factors like fit in the community as contributory factors to employees' staying in the organisation. Because the concept of job embeddedness was developed in the literature on retention and turnover, one would expect the concept to have a strong relationship with the intention to leave and voluntary turnover (Halbesleben \& Wheeler 2008).

Against this background, it is evident that there is a need to explore the turnover behaviour of academic staff. More specifically, studies on the influence of the job embeddedness and organisational commitment of academic staff in relation to whether they stay or leave the organisation would be useful. Studies have been conducted globally to determine the relationship between job embeddedness and organisational commitment in predicting voluntary turnover and turnover intentions (Crossley, Bennet, Jex \& Burnfield 2007; Feldman \& Ng 2007; Harman et al 2007; Holtom \& Inderrieden 2006; Lim \& Wong 2009; Mallol, Holtom \& Lee 2007; Mitchell et al 2001a; Mitchell et al 2001b; Ramesh \& Gelfand 2010), and a few have also been undertaken in South Africa (Heymann 2010; Pillay 2009; Versfeld 2009). In the search to find strategies on how to retain young and skilled academic staff, it would be beneficial to gain insight into the relationship between employees' job embeddedness and organisational commitment on the one hand and voluntary turnover on the other, with a specific focus on how gender, race and age groups differ in terms of their job embeddedness, organisational commitment and turnover intentions.

\section{Aims of the study}

The aims of this study were to explore whether job embeddedness and organisational commitment predict voluntary turnover (intention to stay), and whether people from different gender, race and age groups differ significantly regarding these three variables. In the light of the shortage of young academic staff in higher education institutions in South Africa, this study is expected to contribute to the knowledge base on staff retention in the higher education context.

\section{Job embeddedness}

Job embeddedness refers to a broad array of influences on employee retention that help to explain why people choose to stay in their current employment (Mitchell et al 2001a; Mitchell et al 2001b). The construct of embeddedness describes the forces that influence turnover decisions, focusing on the aspects of fit and structural ties and relationships (Allen 2006). In contrast to the traditional approach to studying voluntary turnover, job embeddedness examines both on-the-job and off-the-job factors that influence a person's decision not to leave the organisation (Mallol et al 2007).

According to Mitchell et al (2001a), an individual can be enmeshed in many different ways, and these are described by three main dimensions, namely links, fit and sacrifice. Links are described as formal or informal connections between people and 
institutions or other people. Numerous strands connect an employee and his or her family in a social, psychological and financial web that includes work and nonwork friends, groups, the community and the physical environment in which he or she lives. The higher the number of links between the person and the web, the more closely an employee is bound to the job and the organisation (Lim \& Wong 2009; Mitchell et al 2001a; Van Dyk 2011).

Fit is defined as an employee's perceived compatibility with or comfort in an organisation and his or her environment. The environment in this sense is taken as embracing both on-the-job and off-the-job experiences (Halbesleben \& Wheeler 2008; Lee \& Mitchell 1994; Mallol et al 2007; Mitchell et al 2001a). With regard to the on-thejob environment, Mitchell et al (2001a) propose that an employee's personal values, career goals and plans for the future must "fit" into the larger corporate culture and the demands of his or her immediate job (say, job knowledge, skills and abilities). Regarding the off-the-job environment, a person would consider how well he or she fits into the community and the surrounding environment. Essentially, the better the fit, the higher the likelihood there is that an employee will feel professionally and personally linked to the organisation (Hom \& Xiao 2011; Mitchell et al 2001a; Yang, Ma \& Hu 2011). The evaluations of fit are not necessarily based on the job or organisation. The job embeddedness model proposes that fit may be independent of the job or organisation, and includes a variety of factors outside the organisation (Halbesleben \& Wheeler 2008; Zhang, Fried \& Griffeth 2012).

Sacrifice describes the perceived cost of material or psychological benefits that may be forfeited by leaving one's job. Leaving an organisation is likely to result in personal losses, whether financial or psychological (Holtom \& O'Neill 2004; Mitchell et al 2001b). Again, there are on-the-job as well as off-the-job losses to be considered. On-the-job losses would include losing contact with colleagues, interesting projects or pleasant benefits (Mitchell et al 2001b). The dimensions and constructs are explained further in Table 1 below in relation to the organisation and the community.

Biographical variables that were found to correlate significantly with job embeddedness include gender, race, and age. Differences in gender were noted by Griffeth, Horn and Gaertner (2000) and Tanova and Holtom (2008). Tanova and Holtom (2008) found that female workers were lower on job embeddedness compared with their male counterparts. Griffeth et al (2000) reported a slight difference between males and females, supporting the findings presented by Tanova and Holtom (2008). However, Allen and Shannock (2012) found contradictory results in that they reported no significant differences between gender groups.

With regard to differences between race groups, Mallol et al (2007), found that job embeddedness statistically predicted voluntary turnover across all races. These findings contradict those reported by Allen and Shannock (2012), who could find no significant differences between race groups.

Griffeth et al (2000) found age-related differences in that the younger the employees were, the lower their job embeddedness. Younger employees are more likely to take risks at the beginning of their careers and to accept positions that are below their abilities and expectations at the beginning of their career and move to better jobs when these become available.

Job embeddedness is a vital construct in trying to understand why people stay with organisations. Job embeddedness attempts to explain employees' attachment behaviour to the organisation (Dawley \& Andrews 2012). In an attempt to retain staff, organisations could integrate on-the-job and off-the-job activities to provide retention 
benefits for both organisations and communities (Crossley et al 2007; Halbesleben \& Wheeler 2008; Lev \& Koslowsky 2009; Mallol et al 2007; Pillay 2009).

Table 1

Description of the job embeddedness dimensions (fit, link \& sacrifice) in relation to the organisation and the community)

\begin{tabular}{|c|c|c|}
\hline Dimension & Constructs & Description \\
\hline \multirow{2}{*}{$\begin{array}{l}\text { Links - measures the } \\
\text { extent to which one } \\
\text { has links with other } \\
\text { people or activities }\end{array}$} & Organisational links & $\begin{array}{l}\text { Considers the formal and informal connections that } \\
\text { exist between an employee and other people, or } \\
\text { groups in the organisation. }\end{array}$ \\
\hline & Community links & $\begin{array}{l}\text { Recognises the significant influence that family and } \\
\text { other social institutions exert on individuals and their } \\
\text { decision making. }\end{array}$ \\
\hline \multirow{2}{*}{$\begin{array}{l}\text { Fit - measures the } \\
\text { extent to which one's } \\
\text { job and communities } \\
\text { are similar to or fit in } \\
\text { with other aspects of } \\
\text { one's life spaces }\end{array}$} & Organisational fit & $\begin{array}{l}\text { Reflects an employee's perceived compatibility or } \\
\text { comfort with the organisation. The person's values, } \\
\text { career goals and plans for the future must fit in with } \\
\text { the broader corporate culture as well as the demands } \\
\text { of the immediate job (e.g. job knowledge, skills and } \\
\text { abilities). }\end{array}$ \\
\hline & Community fit & $\begin{array}{l}\text { Captures how well a person feels that he or she fits } \\
\text { into the community and the surrounding environment. } \\
\text { Includes the weather, amenities and general culture } \\
\text { if the location in which one resides is relevant to } \\
\text { perceptions of community fit. }\end{array}$ \\
\hline \multirow{2}{*}{$\begin{array}{l}\text { Sacrifice - measures } \\
\text { the ease with which } \\
\text { links can be broken if } \\
\text { one had to physically } \\
\text { move to another city } \\
\text { or home }\end{array}$} & $\begin{array}{l}\text { Organisational } \\
\text { sacrifice }\end{array}$ & $\begin{array}{l}\text { Captures the perceived cost of material or } \\
\text { psychological benefits that may be forfeited by } \\
\text { leaving one's job (e.g. giving up colleagues, projects } \\
\text { and perks). The more an employee gives up when } \\
\text { leaving, the more difficult it is to sever employment } \\
\text { with the organisation. }\end{array}$ \\
\hline & Community sacrifice & $\begin{array}{l}\text { This is mostly an issue if one has to relocate. } \\
\text { Leaving a community that is attractive, safe and } \\
\text { where one is liked or respected can be difficult. Even } \\
\text { if one does not necessarily relocate, various } \\
\text { conveniences like an easy commute or flexitime may } \\
\text { be lost by changing jobs. }\end{array}$ \\
\hline
\end{tabular}

Dawley and Andrews (2012) confirm that an employee who is highly engaged may find it difficult to leave his or her job. The difficulty about leaving the job may be the result of the employee's investing so much time and energy in the job. Furthermore, if the organisation provides resources that enable the employee to perform his or her duties successfully, the employee may be hesitant about leaving the organisation (Halbesleben \& Wheeler 2008).

\section{Organisational commitment}

The term "organisational commitment" was first coined by Mowday, Steers and Porter (1979). Since the conceptualisation of organisational commitment, scholars have proposed numerous definitions in an attempt to understand and explain this work attitude. Research by Meyer and Allen (1991) resulted in a widely accepted definition of this work attitude. They state that organisational commitment refers to an inner condition connecting employees to the organisation. This connection typically refers to positive work attitudes or psychological connections shown by an employee towards the organisation. Employees who are committed to their organisation may develop a 
more positive view of the organisation, and their behaviour will be consistent with the expected behaviour in order to avoid cognitive dissonance or to maintain positive selfperceptions (Allen \& Meyer 1990; Meyer, Allen \& Smith 1993; Miller \& Lee 2001).

The Meyer and Allen (1991) three-component model is viewed as a multidimensional construct and measure associated with the conceptualisation of organisational commitment (Meyer \& Allen 1991). The three-component model conceptualises organisational commitment in terms of three approaches, namely affective, continuance and normative commitment. Meyer and Allen (1991) further propose that each component develops as a result of different experiences and has different implications for on-the-job behaviour. The authors assert that the link to these three approaches is the view that commitment is a psychological state that characterises the employee's relationship with the organisation and influences his or her decision to continue or discontinue membership of the organisation.

Affective commitment refers to the employee's emotional attachment to, identification with and involvement in the organisation. Allen and Meyer (1990) contend that employees with a strong affective commitment continue employment with the organisation because they want to (Meyer \& Herscovitch 2001). Continuance commitment describes an awareness of the costs associated with leaving the organisation. This may be likened to the subdimension of sacrifice in job embeddedness. In this instance, those employees whose primary link to the organisation is based on continuance commitment remain because they need to (Meyer \& Allen 1991; Meyer \& Herscovitch 2001). Normative commitment reflects an employee's feeling of being obliged to continue in the employ of the organisation. According to Meyer and Allen (1991), employees with a high level of normative commitment feel they have to remain with the organisation (Meyer \& Herscovitch 2001). Research has found that the biographical variables of gender, race and age significantly influence the organisational commitment of employees (Lumley 2009; Martin \& Roodt 2008; Savicki, Cooley \& Gjesvold 2003).

Regarding gender, the research results are conflicting. Some studies found women to be more committed than men, while others found that men are more committed to the organisation than their female colleagues (Lumley 2009; Martin \& Roodt 2008). Similarly, Savicki et al (2003) state that because men and women experience different sociopsychological realities in the workplace, they are likely to differ significantly in their organisational commitment (Kanwar, Singh \& Kodwani 2012). Lumley, Coetzee, Tladinyane and Ferreira (2011) and Martin and Roodt (2008) found significant differences between race groups with regard to organisational commitment. White research participants reported higher levels of commitment than their black counterparts (Martin \& Roodt 2008).

The findings on age and organisational commitment are contradictory as well. Müller and Roodt (1998) found no relationship between age and organisational commitment, but some studies have reported a positive correlation between the two constructs (Lumley et al 2011; Martin \& Roodt 2008). The positive correlation that was evident is that as people age in the organisation, they become more satisfied with their jobs (Heymann 2010; Kotze \& Roodt 2005).

Employee retention, productivity, quality and financial success are characterised by high performance and high commitment strategies. An integrated set of management strategies is essential to increase an employee's commitment to the organisation (Lesabe \& Nkosi 2007). Management strategies that can be considered to increase organisational commitment and the retention strategies of organisations relate to 
compensation, benefit packages, morale and motivation, career growth and development, leadership, the nature of the job itself, training and development, performance management and the work environment. Lesabe and Nkosi (2007) further posit that if these strategies are implemented and/or improved, the affective commitment levels of employees and consequent organisational performance may be improved.

Paré and Tremblay (2007) highlight the importance of affective and continuance commitment in retaining key staff. Employees develop a stronger affective attachment to the organisation if their experiences in that organisation are consistent with their expectations and their basic needs are satisfied, compared with those employees whose experiences are less satisfying (Paré \& Tremblay 2007). Continuance commitment may develop as employees recognise not only the cost of leaving, but also how they have developed their competencies or skills through their membership of the organisation. This assertion by Paré and Tremblay (2007) is supported by Foong-ming (2008), who argues that organisational support can be used as a management strategy to retain staff. The notion is that an organisation that provides a caring and supportive working environment will enjoy the benefit of having its employees exhibit attachment behaviours towards the organisation and the resultant commitment to achieve organisational goals (João 2010).

In conclusion, João (2010) argues that the relationship between organisational commitment and turnover has been the focus of many studies, with the majority of the findings identifying a negative relationship between organisational commitment and turnover. A strong relationship between organisational commitment and employee retention has been identified in some studies (Meyer et al 1993). The differences between age, gender and racial groups' job satisfaction and organisational commitment have also been studied (Kanwar et al 2012; Lumley 2009; Lumley et al 2011; Martin \& Roodt 2008).

\section{Voluntary turnover}

Voluntary turnover refers to the situation where a "competent and capable" employee terminates his or her employment with the organisation to work for another establishment (Crossley et al 2007; Holtom, Mitchell, Lee \& Eberly 2008; Porter \& Steers 1973; Versfeld, 2009). The conceptualisation of turnover, based on the classical work of March and Simon (1958) focuses on predicting the ease with which an employee could leave an organisation and the desire to do so. Mallol et al (2007) confirm this view and highlight the stance of traditional models of turnover in understating the construct of voluntary turnover. The traditional models of voluntary turnover suggest that people become dissatisfied with their jobs, search for alternative jobs, compare their options with the current job and leave if any of these alternatives are perceived to be better than their current situation (Holtom \& O'Neill 2004). According to Griffeth et al (2000), this approach, although successful in identifying turnover prediction, only explains a limited percentage of resignations.

Developments in the traditional models resulted in a new theory on turnover process, namely the unfolding model of turnover (Lee \& Mitchell 1994). Drawing on image theory, Lee and Mitchell (1994) suggest that turnover decisions are not always the result of accumulated job dissatisfaction and may sometimes occur without much consideration. The unfolding model expands the scope and depth of theory on voluntary turnover in that it proposes that everyone who leaves an organisation uses one of five distinct decision types, defined by the presence or absence of certain 
process characteristics like negative feelings or the consideration of alternative jobs. The decision-making concepts are underpinned in the image theory, which holds that employees conserve mental resources by using decision-making "shortcuts" (Harman et al 2007; (Mitchell et al 2001a; Mitchell et al 2001b).

Mitchell et al (2001a) introduced the concept of a "shock", which is an event that jars employees into thinking seriously about turnover. They proposed that after a shock, some employees automatically follow a "script" and leave their job. This script amounts to a planned series of behaviours reserved for a particular situation in the future. Employees may immediately cast out or "screen out" job alternatives without much thought, based on a mismatch between the individual's values or goals (i.e. mental images) and those represented by the organisation in question. This mismatch is referred to in the theory as an "image violation".

The theory advanced is that turnover decisions are not always the result of accumulated job dissatisfaction and may sometimes occur without much deliberation (Lee \& Mitchell 1994). Certain events may cause some employees to consider leaving their organisations when the event matches some pre-existing plan for leaving, violates employees' values or interferes with their goal attainment (Lee \& Mitchell 1994).

\section{Research design}

\section{Research participants}

The population consisted of 1018 permanently employed academic staff from two colleges at a higher education institution situated in Gauteng, namely the College of Economic and Management Sciences and the College of Human Sciences at the institution. The study adopted a random sampling technique, based on Cohen's (1992) guidelines, to determine the sample size. A random sample of $300(\mathrm{~N}=300)$ academics were invited to participate in the study. Participants were requested to complete a webbased questionnaire, resulting in a final sample of 102 respondents $(N=102)$ and a response rate of $34 \%$.

The sample size was skewed towards females (53\%) between the ages of 40 and 59 years $(58 \%)$ with master's degrees $(40 \%)$. In terms of race, the majority of the sample were white (59\%), followed by African (34\%), Asian (4\%) and coloured (3\%).

\subsection{Measuring instruments}

The measuring battery consisted of the Job Embeddedness Scale (JES) (Lee \& Mitchell 1994), the Organisational Commitment Scale (OCS) (Meyer \& Allen 1991) and the Voluntary Turnover Scale (VTS) (Crossley et al 2007).

The JES (Lee \& Mitchell 1994) is a 32-item scale used to measure the participants' level of job embeddedness on a six-point Likert scale ranging from 1 (strongly disagree) to 6 (strongly agree). The JES measures the dimensions of fit, link and sacrifice against the elements of the organisation and the community (Lee \& Mitchell 1994). The core dimensions measured in this study were organisational fit (9 items), organisational sacrifice (10 items), community fit (5 items), community link (5 items) and community sacrifice (3 items). Questions on the scale include "My job utilizes my skills and talents well" and "The health-care benefits provided by this organisation are excellent". Mitchell et al (2001a) reported the following internal consistency reliabilities per subscale for the instrument: organisational fit $(0.75)$, organisational links $(0.65)$, organisational sacrifice $(0.82)$, community fit $(0.78)$, community links $(0.77)$ and community sacrifice $(0.61)$. In the current study, the Cronbach's alpha coefficients varied from 0.60 to 0.87 . 
To measure the participants' level of organisational commitment, the OCS (Meyer \& Allen 1991) was used. The OCS is a 22-item scale measuring the three main subscales, namely affective (8 items), continuance (8 items) and normative commitment (6 items). The subscales were measured on a six-point Likert scale, ranging from 1 (strongly disagree) to 6 (strongly agree). Questions on the scale include "I would be very happy to spend the rest of my career with this organisation"; "I do not feel emotionally attached to this organisation" and "This organisation deserves my loyalty". Van Dyk and Coetzee (2012) reported high internal consistency reliabilities for affective commitment (0.90), continuance commitment $(0.84)$ and normative commitment (0.70). The Cronbach alpha coefficients for the three subscales obtained from the sample in this study varied from 0.57 to 0.71 . Continuance commitment, a subscale of the OCS, reported a low overall reliability $(0.57)$, resulting in its exclusion from all statistical analyses.

The Voluntary Turnover Scale (VTS) (Crossley et al 2007) was used to measure the participants' level of voluntary turnover (intention to stay). The VTS scale comprises four items measured on a six-point Likert scale, ranging from 1 (strongly agree) to 6 (strongly disagree). Questions on the scale include "My co-workers make me feel welcome here", and "My co-workers make me feel wanted here". Higher scores indicated lower intention to leave and higher intention to stay. Crossley et al (2007) found the instrument to be reliable $(0.69)$. The Cronbach alpha coefficient of the VTS, obtained from the sample in this study, was 0.76 .

\subsection{Research procedure}

A cross-sectional quantitative survey research design was used for this study. Survey research allows for the collection of information from the respondents about their beliefs, opinions, characteristics and past or present behaviour (Maree 2009; Neuman 2006; Oates, Griffiths, Lockyer \& Hebbron 2004). Ethical clearance to conduct the research was obtained from the management and Research Ethics Committee of the higher education institution. The database containing the list of academic staff members at the two colleges who participated in the study was obtained from the Human Resources Department. An invitation to participate in the study was then sent out to these respondents. The sample of respondents was requested to participate voluntarily in the research by completing the questionnaires. The questionnaires were sent to the respondents using LimeSurvey software, which is designed to circulate electronic surveys. A message accompanying the e-mail was included to explain the purpose of the study, and ethical concerns such as confidentiality, anonymity and freedom of choice to participate in the study were emphasised. The completed questionnaires were kept in a secure place to which only the LimeSurvey administrator had the necessary access to send reminders and view the number of completed questionnaires.

\subsection{Statistical analyses}

The SPSS (Version 20) was used to analyse the data of the empirical study. Descriptive statistics (means and standard deviations) and Cronbach's alpha coefficients were calculated to determine the internal consistency reliability of the three measures. Multiple regression analyses were performed to achieve the research objective. The value of adjusted $R^{2}$ was used to determine the proportion of the total variance of the dependent variable (VTS) that is explained by the independent variables (JES and OCS). The F-test was used to test whether there was a significant 
regression ( $p \leq 0.05)$ between the independent and dependent variables. For the purposes of this study, significant $R^{2}$ values greater than 0.13 (medium effect) (Cohen 1992) were regarded as practically significant.

The independent samples T-test was used to measure significant differences between the mean scores of the gender groups on the JES and the OCS. The MannWhitney $U$ test was used to measure significant differences between the mean scores of the gender groups on the VTS. ANOVAs were used to measure significant differences between the mean scores of the race and age groups in terms of their job embeddedness and organisational commitment. The Kruskal-Wallis test was used to measure significant differences between the mean scores of the race and age groups in terms of their voluntary turnover (intention to stay). In order to counter the probability of a Type I error, it was decided to set the significance value for interpreting the results at a $95 \%$ confidence interval level $(F p \leq 0.05)$. Eta squared $\left(\eta^{2}\right)$ values greater than 0.09 (medium effect) were regarded as practically significant.

\section{Results}

\subsection{Descriptive statistics}

Table 2 shows the means and standard deviations for job embeddedness (JES), organisational commitment (OCS) and voluntary turnover (intention to stay) (VTS). The highest mean score obtained was on the organisational fit subscale $(M=4.60$; $S D=0.82)$, and the lowest on the community sacrifice subscale $(M=3.78 ; S D=1.31)$. Overall, the JES indicated a right-skewed distribution (0.06). All the subscales of the JES indicated a left-skewed distribution (skewness $<0$ ). The skewness values ranged from -0.14 to -0.95 , thus falling within the normality range $(Z= \pm 1)$ (Howell 2010:74). The kurtosis values ranged from -0.14 to 1.08 , indicating that the probability for extreme values was less than for a normal distribution (Brown 1997). The values were therefore spread around the mean.

Table 2

Cronbach alpha coefficients, means and standard deviations $(\mathrm{N}=102)$

\begin{tabular}{|l|c|c|c|c|c|}
\hline \multicolumn{1}{|c|}{ Variables } & $\begin{array}{c}\text { Cronbach } \\
\text { alpha }\end{array}$ & Mean & SD & Skewness & Kurtosis \\
\hline Organisational fit (JES) & 0.82 & 4.60 & 0.82 & -0.92 & 1.08 \\
\hline Organisational sacrifice (JES) & 0.83 & 4.10 & 0.92 & -0.30 & -0.14 \\
\hline Community fit (JES) & 0.87 & 4.50 & 1.10 & -0.95 & 1.32 \\
\hline Community link (JES) & 0.60 & 3.74 & 1.29 & -0.25 & -0.61 \\
\hline Community sacrifice (JES) & 0.72 & 3.78 & 1.31 & -0.14 & -0.88 \\
\hline Affective commitment (OCS) & 0.71 & 3.82 & 0.63 & 0.66 & 1.80 \\
\hline Normative commitment (OCS) & 0.71 & 3.68 & 1.05 & -0.34 & -0.24 \\
\hline Voluntary turnover (VTS) & 0.76 & 4.07 & 1.14 & -1.21 & 1.25 \\
\hline
\end{tabular}

The sample of the participants obtained the highest mean score on the OCS affective commitment subscale $(M=3.82 ; S D=0.63)$ and the lowest on the normative commitment subscale $(M=3.68 ; S D=1.05)$. Overall, the OCS indicated a left-skewed distribution (0.57). However, the skewness values of the affective and normative commitment subscales ranged from -0.34 to 0.66 , thus falling within the normality range $(Z= \pm 1)$ (Howell 2010: 74). The kurtosis values ranged from -0.24 to 1.80 , indicating that the probability for extreme values was less than for a normal distribution (Brown 1997), which suggests that the values were spread around the mean. 
With regard to voluntary turnover, the total average mean score of the VTS was $M=4.07$ ( $S D=0.94)$, indicating low voluntary turnover (high intention to stay). The VTS points to a right-skewed distribution $(-1.08)$. This is an indication that the distribution was flatter than a normal distribution $(Z= \pm 1)$ (Howell 2010:74). The kurtosis value was 1.99 , which suggests that the probability for extreme values was higher than for a normal distribution (Brown 1997).

\subsection{Multiple regression analyses}

Table 3 summarises the regression model between the independent variables (job embeddedness and organisational commitment) and the dependent variable (voluntary turnover). The regression of the JES variables on voluntary turnover produced a statistically significant model $(F=12.54 ; p=0.000)$, accounting for $36 \% \quad\left(R^{2}=0.36\right.$; medium practical size effect) of the variance in the voluntary turnover variable. Organisational fit $(\beta=0.58 ; p=0.000)$ and community link $(\beta=0.19 ; p=0.04)$ contributed significantly and positively to explaining the variance in voluntary turnover (intention to stay). The results from the regression analysis indicate that job embeddedness variables (organisational fit and community link) could explain why academics intend to stay at the organisation. Sacrifice (organisational and community) and community fit did not significantly predict voluntary turnover (intention to stay). Similarly, the regression of the OCS variables on voluntary turnover produced a statistically significant model $(F=7.51 ; p=0.000)$, accounting for $11 \%\left(R^{2}=0.11\right.$; small practical size effect) of the variance. Normative commitment $(\beta=0.36 ; p=0.000)$ contributed significantly and positively to explaining the variance in voluntary turnover (intention to stay). Essentially, normative commitment explained why academics intend to stay at the organisation. Affective commitment did not significantly predict voluntary turnover (intention to stay).

Table 3

Multiple regression statistics summary: voluntary turnover as the dependent variable and job embeddedness and organisational commitment as the independent variables

\begin{tabular}{|c|c|c|c|c|c|c|c|c|}
\hline \multirow[t]{2}{*}{ Variable } & \multicolumn{2}{|c|}{$\begin{array}{l}\text { Unstandardised } \\
\text { coefficient }\end{array}$} & \multirow{2}{*}{$\begin{array}{c}\begin{array}{c}\text { Standardised } \\
\text { coefficient }\end{array} \\
\text { Beta }(\beta)\end{array}$} & \multirow[t]{2}{*}{$\mathbf{T}$} & \multirow[t]{2}{*}{$p$} & \multirow[t]{2}{*}{$\mathbf{F}$} & \multirow{2}{*}{$\begin{array}{c}\text { Adjusted } \\
\qquad R^{2}\end{array}$} & \multirow[t]{2}{*}{$\mathbf{R}$} \\
\hline & B & Std error & & & & & & \\
\hline JES (Constant) & 0.82 & 0.58 & & 1.41 & 0.000 & $12.54^{\star \star \star}$ & $0.36+++$ & 0.63 \\
\hline Organisational fit & 0.81 & 0.15 & .58 & 5.61 & $0.000^{* * *}$ & & & \\
\hline $\begin{array}{l}\text { Organisational } \\
\text { sacrifice }\end{array}$ & 0.99 & 0.13 & .08 & 0.78 & 0.44 & & & \\
\hline Community fit & -0.17 & 0.11 & -.17 & -1.57 & 0.12 & & & \\
\hline Community link & 0.19 & 0.09 & .22 & 2.14 & $0.04^{*}$ & & & \\
\hline $\begin{array}{l}\text { Community } \\
\text { sacrifice }\end{array}$ & -0.06 & 0.09 & -.07 & -0.59 & 0.56 & & & \\
\hline OCS (Constant) & 3.74 & 0.73 & & 5.12 & 0.000 & $7.51^{* \star *}$ & $0.11+$ & 0.36 \\
\hline Affective & -0.13 & 0.17 & -.07 & -0.78 & 0.44 & & & \\
\hline Normative & 0.39 & 0.10 & .36 & 3.85 & $0.000^{* * *}$ & & & \\
\hline
\end{tabular}

${ }^{* \star *} p \leq 0.001 ;{ }^{* *} p \leq 0.01 ;{ }^{*} p \leq 0.05$

$+R^{2} \leq 0.12$ (small practical size effect); $++R^{2} \geq 0.13 \leq 0.25$ (medium practical size effect; $+++R^{2} \geq 0.26$ (large practical size effect)

\subsection{Tests for significant mean differences between gender groups}

As shown in Table 4, no significant differences were found between the gender groups regarding the JES community fit, links and sacrifice variables and the OCS affective and normative commitment variables. However, significant differences were evident in the JES organisational fit and organisational sacrifice variables. Table 3 shows that the 
females obtained a significantly higher mean score $(M=4.77)$ for organisational fit compared with their male counterparts $(M=4.40)$. The females also obtained a higher mean score $(M=4.30)$ than the males $(M=3.88)$ for organisational sacrifice.

Table 4

Significant mean differences: independent T-tests for gender groups (JES and OCS)

\begin{tabular}{|c|c|c|c|c|c|c|c|c|c|}
\hline \multirow[t]{2}{*}{ Variable } & \multirow{2}{*}{$\begin{array}{l}\text { Gender } \\
\text { group }\end{array}$} & \multirow[t]{2}{*}{$\mathbf{N}$} & \multirow[t]{2}{*}{ Mean } & \multirow[t]{2}{*}{ SD } & \multicolumn{2}{|c|}{$\begin{array}{l}\text { Levene's test } \\
\text { for equality of } \\
\text { variance }\end{array}$} & \multicolumn{3}{|c|}{$\begin{array}{l}\text { T-test for equality of } \\
\text { means }\end{array}$} \\
\hline & & & & & $\mathbf{F}$ & Sig. & $\mathbf{T}$ & df & $\begin{array}{c}\text { Sig. } \\
\text { (2-tailed) }\end{array}$ \\
\hline \multirow{2}{*}{ Organisational fit (JES) } & Male & 48 & 4.40 & .88 & \multirow{2}{*}{4.01} & \multirow{2}{*}{.05} & \multirow{2}{*}{-2.35} & \multirow{2}{*}{100} & \multirow{2}{*}{$.02^{*}$} \\
\hline & Female & 54 & 4.77 & .73 & & & & & \\
\hline \multirow{2}{*}{$\begin{array}{l}\text { Organisational sacrifice } \\
\text { (JES) }\end{array}$} & Male & 48 & 3.88 & .99 & \multirow{2}{*}{1.09} & \multirow{2}{*}{.30} & \multirow{2}{*}{-2.32} & \multirow{2}{*}{100} & \multirow{2}{*}{$.02^{*}$} \\
\hline & Female & 54 & 4.30 & .81 & & & & & \\
\hline
\end{tabular}

${ }^{* * *} p \leq 0.001 ;{ }^{* *} p \leq 0.01 ;{ }^{*} p \leq 0.05$

As shown in Table 5 , the Mann-Whitney $U$ test indicated significant mean differences between the male $(M=4.47)$ and female $(M=4.88)$ participants at $p=0.04$. The results show that the female participants seem more likely to remain with the organisation than the male participants.

Table 5

Significant mean results (Mann-Whitney): gender (VTS)

\begin{tabular}{|l|c|c|c|c|c|c|}
\hline Variable & N & $\begin{array}{c}\text { Mean } \\
\text { rank }\end{array}$ & Mean & $\begin{array}{c}\text { Z- } \\
\text { value }\end{array}$ & p-value & Mann-Whitney \\
\hline Males & 48 & 45.23 & 4.47 & \multirow{2}{*}{$-2.03^{*}$} & $0.04^{*}$ & 995.00 \\
\hline Females & 54 & 57.07 & 4.88 & & \\
\hline
\end{tabular}

${ }^{*} p \leq 0.05$

\subsection{Tests for significant mean differences between race groups}

Overall, Table 6 shows that the race groups did not differ significantly in respect of the JES organisational fit and organisational sacrifice variables and the OCS affective

Table 6

Significant mean differences (ANOVAs): race groups (JES and OCS)

\begin{tabular}{|c|c|c|c|c|c|c|c|c|c|}
\hline Variable & $\begin{array}{l}\text { Race } \\
\text { group }\end{array}$ & $\mathbf{N}$ & Mean & SD & $\mathbf{F}$ & df & $\begin{array}{l}\text { Sig. level } \\
\text { (2-tailed) }\end{array}$ & Eta & $\begin{array}{c}E^{E t a}{ }^{2} \\
\eta^{2}\end{array}$ \\
\hline \multirow{4}{*}{ Community fit (JES) } & White & 60 & 4.75 & 0.88 & \multirow{4}{*}{2.88} & \multirow{4}{*}{101} & \multirow{4}{*}{$0.04^{*}$} & \multirow{4}{*}{0.29} & \multirow{4}{*}{$0.08+$} \\
\hline & African & 35 & 4.18 & 1.25 & & & & & \\
\hline & Coloured & 3 & 3.80 & 0.20 & & & & & \\
\hline & Asian & 4 & 4.00 & 2.02 & & & & & \\
\hline \multirow{4}{*}{ Community link (JES) } & White & 60 & 4.12 & 1.15 & \multirow{4}{*}{5.32} & \multirow{4}{*}{101} & \multirow{4}{*}{$0.002^{* * *}$} & \multirow{4}{*}{0.37} & \multirow{4}{*}{$0.14++$} \\
\hline & African & 35 & 3.10 & 1.33 & & & & & \\
\hline & Coloured & 3 & 3.40 & 0.53 & & & & & \\
\hline & Asian & 4 & 3.95 & 1.42 & & & & & \\
\hline \multirow{4}{*}{$\begin{array}{l}\text { Normative commitment } \\
\text { (OCS) }\end{array}$} & White & 60 & 3.50 & 0.92 & \multirow{4}{*}{5.32} & \multirow{4}{*}{101} & \multirow{4}{*}{$0.002^{* * *}$} & \multirow{4}{*}{0.37} & \multirow{4}{*}{$0.14++$} \\
\hline & African & 35 & 4.16 & 0.99 & & & & & \\
\hline & Coloured & 3 & 2.83 & 1.00 & & & & & \\
\hline & Asian & 4 & 2.75 & 1.76 & & & & & \\
\hline
\end{tabular}

${ }^{* * *} p \leq 0.001 ;{ }^{* *} p \leq .01 ;{ }^{*} p \leq 0.05$

$+\eta^{2} \leq 0.08=$ small practical effect; $++\eta^{2} \geq 0.09 \leq 0.24=$ moderate practical effect 
commitment variable. The white participants value community fit $\left(M=4.75 ; \eta^{2}=0.08\right.$; small practical effect) and community links $\left(M=4.12 ; \eta^{2}=0.14\right.$; moderate practical effect) with regard to their intention to stay at the organisation. Table 6 also indicates that the African participants seem to place more value on normative commitment regarding their intention to stay at the organisation than the other race groups $\left(M=4.16 ; \eta^{2}=0.14\right.$; moderate practical effect).

In terms of the VTS, a Kruskal-Wallis test showed no significant differences between the mean scores of the race groups. The results are therefore not reported here for reasons of space.

\subsection{Tests for significant mean differences: age groups}

Results of the ANOVA (JES and OCS) and Kruskal-Wallis (VTS) tests showed no significant differences between the mean scores of the various age groups at $p \leq 0.05$; hence the results will not be reported in table format for reasons of space.

\section{Discussion}

The current study contributes to the retention literature by exploring whether academic staff's job embeddedness and organisational commitment significantly and positively predict their voluntary turnover (intention to stay) at the higher education institution, and whether the gender, race and age groups differ significantly in terms of these three variables.

\subsection{Job embeddedness and organisational commitment as predictors of voluntary turnover (intention to stay)}

Overall, the results showed that the participants' job embeddedness (organisational fit and community link) and their organisational commitment (normative commitment) contributed significantly to explaining their decision to stay at the organisation. The findings indicated that the participants who had a high sense of compatibility with the organisation (fit) and who perceived their values, career goals and plans for the future to fit in with the larger corporate culture as well as the demands of the immediate job (community link) (Holtom \& Inderrieden 2006) showed significantly stronger intentions to stay with the higher education institution. Lev and Koslowsky (2009) posit that workers high on organisational fit and link seem to be more sensitive to the benefits associated with the job and are conscious of the cost of leaving (sacrifice) involved, should they leave the organisation.

Similarly, those participants who had strong community links and high levels of normative commitment also showed significantly stronger intentions to stay. Studies by Dawley and Andrews (2012), Halbesleben and Wheeler (2008) and Ramesh and Gelfand (2010) also indicate strong positive associations between employees' job embeddedness, organisational commitment and intention to stay. Lev and Koslowsky (2009) conducted a study among school teachers and found that the higher the teachers rated their fit in the organisation and the more they established links in the organisation, the more likely they were to stay with the organisation. According to Meyer and Herscovitch (2001), normative commitment reflects the employee's feeling obliged to remain at the organisation. The positive association between the participants' normative commitment and their intention to stay could be explained by the participants' feeling obliged to remain at the organisation because of the support provided in the form of payment for their tuition and training and development, as 
suggested by Meyer and Allen (1991). South African-based research by Ferreira, Basson and Coetzee (2010), Lumley et al (2011) and Manetje and Martins (2009) also indicates that employees feel obliged to remain in the organisation when it supports them in the form of paying their tuition and training and development fees. In addition to these strategies, employees seem to remain loyal to an organisation that makes visible attempts to encourage their work-life balance (Muteswa \& Ortlepp 2011). The more committed employees are to the organisational values and norms, the less likely they are to leave the organisation (Manetje \& Martins 2009). Employees who were satisfied with the social norms of the organisation seem likely to remain with the organisation (Ferreira et al 2010; Lumley et al 2011).

Lev and Koslowsky (2009) conducted a study among school teachers and found that the higher the teachers rated their fit in the organisation and the more links they established in the organisation, the more likely they were to stay with the organisation. Lev and Koslowsky (2009) further posited that workers high on organisational fit and links seem to be more sensitive to the benefits associated with the job and are conscious of the cost of leaving (sacrifice) involved, should they leave the organisation. Allen and Shannock (2012), Halbesleben and Wheeler (2008) and Holtom and Inderrieden (2006) supported the findings of Lev and Koslowsky (2009). A clearly formulated orientation programme would result in more highly embedded newcomers, instil a high sense of loyalty to the organisation and indirectly result in lower turnover intention.

Regarding organisational commitment, normative commitment related significantly to the participants' job embeddedness and their intention to stay at the institution. According to Meyer and Herscovitch (2001), normative commitment reflects the employee's feeling obliged to remain at the organisation (Meyer \& Allen 1991). Meyer and Allen (1991) further argue that employees may feel obliged to remain at the organisation when it provides support in the form of paying for their tuition and training and development. Ferreira et al (2010), Lumley et al (2011) and Manetje and Martins (2009) confirm the assertions made by Allen and Meyer (1990).

\subsection{Differences between the gender, race and age groups}

Overall, the results showed that the female and male, and white and African participants differed significantly regarding job embeddedness and voluntary turnover (intention to stay).

Gender groups: The female research participants, compared with their male counterparts, had significantly stronger perceptions of job embedded-fit and what they would sacrifice if they were to decide to leave the institution. The female participants also indicated stronger intentions to stay, compared with the male participants. It appears that the female participants feel that they fit in with their group members, that their personal values, goals and aspirations agree with the organisational values and that there are opportunities for professional growth in the organisation (Holtom \& Inderrieden 2006). The findings of the present study could be attributed to the employment equity policies of the institution, which tend to favour the career and personal development of female academics (Bezuidenhout \& Cilliers 2011; Ngobeni \& Bezuidenhout 2011; Rabe \& Rugunanan 2012). The employment equity incentives for women and the flexible working hours they are permitted may have resulted in their feeling that they are advantaged by the organisation's policies and that they would sacrifice a lot if they decided to leave. The findings of the current study contradict those reported by Epstein, Saute, Oglensky and Gever (1995), Griffeth et al (2000), Kanwar et al (2012), Tanova and Holtom (2008), which indicate that female workers show lower 
attachment behaviour and higher tendencies to leave the organisation compared with male workers.

Race groups: The white participants showed significantly higher levels of jobembedded community fit and links compared with the other race groups. The findings of the current study indicate that the white participants, who constituted the majority of the sample, love the place they live in; feel the community is a good match for them; and are conscious that they have family members nearby. This finding may be attributed to the fact that the higher education institution was historically a white majority institution and that the white participants could therefore still feel deeply embedded in the organisational and social culture and have formed close links with the social community. It can also be assumed that the institution promotes work-life balance by means of flexible working hours, resulting in the participants' finding fit, not only with the organisation, but also with the broader community. Donnelly and Quirin (2006) found that organisations can effectively alter the turnover decisions of staff by implementing initiatives pertaining to family and educational endeavours. Research suggests that family initiatives may include flexible working environments (Bezuidenhout \& Cilliers 2011; Donnelly \& Quirin 2006; Nwokocha \& Iheriohamma 2012), while educational endeavours include educational incentive programmes (Ngobeni \& Bezuidenhout 2011).

The findings of the current study indicate that the African participants had higher levels of normative commitment (feeling obliged to stay with the institution) compared with the other race groups. These results may be attributed to the current affirmative action and employment equity programmes, which result in Africans being advantaged for certain developmental and promotion incentives. Research shows that normative commitment is pivotal when an employee is faced with the decision to either stay with or leave the organisation (Döckel, Basson \& Coetzee 2006; Ferreira et al 2010; Lesabe \& Nkosi 2007; Lumley et al 2011; Manetje \& Martins 2009; Martin 2008; Van Dyk 2011; Yang, Che \& Spector 2008).

Age groups: There were no significant differences between the respondents from different age groups in terms of their job embeddedness, organisational commitment and voluntary turnover intention. This contradicts the findings of Griffeth et al (2000), who reported that the younger the employees, the lower their job embeddedness. The findings of the current study, however, confirm those of Müller and Roodt (1998), who found no relationship between age and organisational commitment. This finding merits further research.

\section{Conclusions, implications and recommendations}

Overall, the study contributed valuable new knowledge with regard to the retention of academic staff at the higher education institution. The results show that participants who are highly job embedded are more likely to remain with the organisation. The results of the current study further confirm that employees who find fit with the organisation, especially with the organisation's culture, and feel that the values of the organisation are compatible with their own personal values, find it difficult to leave the community and perceive the cost of leaving the organisation to be high. This fit within the organisation and community results in employees' retaining their citizenship in the organisation. It is evident from the findings that normative commitment (feeling obliged to stay) relates significantly to voluntary turnover. Individuals who feel obliged to continue employment (because they identify with the norms and values of the 
organisation or because of the perceived benefits they receive from the organisation) tend not to consider leaving.

In the affirmative action and employment equity context, the institution should take note of how females and males and race groups differ in terms of their job embeddedness (organisational fit and community links), normative commitment and intention to stay. The current incentives provided to employment equity groups (Africans and women) at the institution seem to have contributed to their perceived organisational fit and normative commitment. Bezuidenhout and Cilliers (2011) suggest that, in addition to the current employment equity initiatives, institutions of higher education should develop academic leadership programmes and "research incubators". The academic leadership programme is a strategy that could be used to encourage young female academics to work towards higher levels in academia, and research incubators could help female academics to become productive researchers and to publish prolifically. The adoption of such visible development programmes could help to instil feelings of loyalty and obligation to remain with the organisation (Bezuidenhout \& Cilliers 2011; Meyer \& Herscovitch 2001).

Research also indicates that it is important to consider work-life balance when attempting to increase academics' normative commitment. Ryan, Healy and Sullivan (2012) conducted a study at a public research university in order to identify the turnover intentions of academic staff. The study focused on the intentions of academic staff to leave the institution and academia generally. Pertinent to the findings of the current study was the emphasis on factors outside the immediate work environment. These authors found that if there is an increase in frustrations associated with family life and raising a family as well as in dissatisfaction with certain aspects of the job (salary, autonomy, teaching load, opportunities for career advancement and for developing new ideas and pursuing research), there is a greater likelihood of an academic staff member's leaving the institution (Ryan et al 2012).

Considering the diverse multicultural workforce of South Africa, the observed differences between the biographical groups' job embeddedness and organisational commitment need to be considered when adopting talent retention strategies. The following factors could be taken as having a bearing on retention strategies in higher education institutions:

- Having a clearly formulated orientation programme so as to help new entrants to improve the way they fit into the organisation. Successful orientation strategies result in subsequent longevity in the organisation (Allen \& Shannock 2012). Considering that the majority of participants were in the early and middle career phase of their lives, it is likely that these participants had found a fit between themselves and the organisation and would have considered their family and other links in the community when faced with the decision to leave or stay with the organisation.

- Organisations should have clearly documented polices on promotions and training. This would ensure that the new hires and current employees are aware of career development opportunities and how they can achieve career growth in the organisation (Ngobeni \& Bezuidenhout 2011).

- Designing employee assistance programmes may be another mechanism that organisations could use in an attempt to retain their employees (Halbesleben \& Wheeler 2008; Wheeler, Gallagher, Brouer \& Sablynski 2007). Allen and Shannock (2012) argue that the positive socialisation of new hires leads to higher perceived organisational support and embeddedness, resulting in lower turnover of staff. It is 
therefore necessary to encourage socialisation of younger new hires with experienced members in the organisation. This will improve embeddedness and consequently reduce staff turnover. The idea behind this is that if employees can obtain assistance for off-the-job issues, they are more likely to stay in the organisation.

- Another strategy that could be considered as a means of promoting organisational fit would be to provide career mobility opportunities in the organisation. Such initiatives could include opportunities for promotion and training and development. It is therefore suggested that the provision of career opportunities could be used to increase overall job embeddedness and organisational commitment (normative and continuance), which could lead to a higher intention to remain with the organisation (Lesabe \& Nkosi 2007);

- Organisational support could take the form of feedback from supervisors on work done, thereby providing a caring work environment by giving direction to employees and also recognising work of a high standard. This would reassure employees that they are contributing something to the organisation and inculcate a sense of fit (Bambacas \& Kulik 2012; Ngobeni \& Bezuidenhout 2011).

- The provision of generous total benefit packages, other than remuneration, is a strategy an organisation could apply in an attempt to lower the staff turnover levels. Mohlala, Goldman and Goosen (2012) argue that an improvement of certain organisational factors tends to be more beneficial than a larger salary. These could include employee assistance programmes, flexible working practices and familyfriendly policies (Du Plessis, Paine \& Botha 2012; Grobler \& De Bruyn 2011; Mohlala et al 2012; Ryan et al 2012).

\section{Limitations and recommendations for future research}

The main limitations of the current study include the small sample size and the limited number of items in the Voluntary Turnover Scale (only 4). This posed a challenge, statistically, in that it was difficult to ascertain whether the variable had been accurately measured. The sample size was not representative in terms of the gender, age and race of the population, implying that the findings of this study cannot be generalised to a larger more heterogeneous sample. Low internal reliabilities for continuance commitment were recorded, resulting in continuance commitment being excluded from all the statistical analyses. Given the cross-sectional nature of the research design, the researchers could not draw any conclusions about causation, since the associations between the variables were interpreted rather than established. It would be beneficial, in future, to replicate this study with broader samples across various occupational, gender, race and age groups before drawing final conclusions about the relationship between individuals' job embeddedness, organisational commitment and voluntary turnover.

Despite the above-mentioned limitations, the results of this study indicate a potential relationship between job embeddedness, organisational commitment and voluntary turnover. Moreover, because the study was conducted in a different context from previous studies, it introduced a different perspective and suggested new areas for further research in respect of the variables investigated. The study further highlights directions that organisations can adopt in developing retention strategies in view of the changing nature of the work and needs of employees, with specific reference to the higher education context. 


\section{List of references}

Allen, DG. 2006. Do organisational socialisation tactics influence newcomer embeddedness and turnover? Journal of Management 32(2):237-256.

Allen, DG \& Shannock, LR. 2012. Perceived organisational support and embeddedness as key mechanisms connecting socialisation tactics to commitment and turnover among new employees. Journal of Organisational Behaviour, DOI:10.1002/job.

Allen, NJ \& Meyer, JP. 1990. The measurement and antecedents of affective, continuance and normative commitment to the organisation. Journal of Occupational Psychology 63:1-18.

Bambacas, M \& Kulik, CT. 2012. Job embeddedness in China: How HR practices impact turnover intentions. The International Journal of Human Resource Management, DOI:10.1080/09585192.2012.725074.

Bezuidenhout, A \& Cilliers F. 2011. Age, burnout, work engagement and sense of coherence in female academics in two South African universities. South African Journal of Labour Relations 35(1):61-80.

Brown, JD. 1997. Skewness and kurtosis. JALT Testing and Evaluation Newsletter, $1(1): 20-23$.

Cohen, J. 1992. Statistical power analysis. Current Directions in Psychological Science 1(3):98-101.

Crossley, G, Bennet, RJ, Jex, SM \& Burnfield, JL. 2007. Development of a global measure of job embeddedness and integration into a traditional model of voluntary turnover. Journal of Applied Psychology 92(4):1031-1042.

Dawley, DD \& Andrews, MC. 2012. Staying put: Off-the-job embeddedness as a moderator of the relationship between on-the-job embeddedness and turnover intentions. Journal of Leadership and Organisational studies 20(10):1-9.

Döckel, A, Basson, JS \& Coetzee, M. 2006. The effect of retention factors on organisational commitment: An investigation of high technology employees. South African Journal of Human Resource Management 4(2):20-28.

Donnelly, DP \& Quirin, JJ. 2006. An extension of Lee and Mitchell's unfolding model of voluntary turnover. Journal of Organisational Behaviour 27:59-77.

Du Plessis, AJ, Paine, S \& Botha, CJ. 2012. The role of human resource practitioners in maintaining sustainability in organisations: Some empirical evidence of expectations, challenges and trends. International Journal of Contemporary Business Studies 3(4):16-35

Epstein, CF, Saute, R, Oglensky, B \& Gever, M. 1995. Glass ceilings and open doors: Women's advancement in the legal profession 64 Fordham Law: 291-447.

Feldman, DC \& Ng, TWH. 2007. Careers: Mobility, embeddedness and success. Journal of Management 33(3):350-377.

Ferreira, N, Basson, J \& Coetzee, M. 2010. Psychological career resources in relation to organisational commitment: An exploratory study. South African Journal of Human Resource Management 8(1):1-10.

Firth, L, Mellor, DJ, Moore, KA \& Loquet, C. 2003. How can managers reduce employee intention to quit? Journal of Managerial Psychology 19(2):170-187.

Foong-ming, T. 2008. Linking career development practices to turnover intention: The mediator of perceived organisational support. Journal of Business and Public Affairs 2(1):1-20. 
Griffeth, RW, Horn, PW \& Gaertner, S. 2000. Meta-analysis of antecedents and correlates of employee turnover: Update, moderator tests, and research implications for the next millennium. Journal of Management, 26(3):463-488.

Grobler, PA \& De Bruyn, AJ. 2011. Flexible work practices (FWP): An effective instrument in the retention of talent: A survey of selected JSE listed companies. South African Journal of Business Management 42(4):63-78.

Halbesleben, JRB \& Wheeler, AR. 2008. The relative roles of engagement and embeddedness in predicting job performance and intention to leave. Work and Stress 22(3):242-256.

Harman, WS, Lee, TW, Mitchell, TR, Felps, W \& Ownes, BP. 2007. The psychology of voluntary employee turnover. Current Directions in Psychological Science 16(1):51-54.

Heymann, M. 2010. The impact of demographics on voluntary labour turnover in South Africa. MBA dissertation, University of Pretoria.

Holtom, B \& O'Neill, B. 2004. Job embeddedness: A theoretical foundation for developing a comprehensive plan for retaining health care employees. Journal of Nursing Administration 34(5):216-227.

Holtom, BC \& Inderrieden, EJ. 2006. Integrating the unfolding model and job embeddedness model to better understand voluntary turnover. Journal of Managerial Issues 18(4):435-452.

Holtom, BC, Mitchell, TR, Lee, TW \& Eberly, MB. 2008. Turnover and retention research: A glance at the past, a closer review of the present, and a venture into the future. The Academy of Management Annuals 2(1):231-274.

Hom, PW \& Xiao, Z. 2011. Embedding social networks: How Guanxi ties reinforce Chinese employees' retention. Organizational Behavior and Human Decision Processes 116:188-202.

Howell, DC. 2010. Fundamental statistics for the behavioral sciences. Wadsworth: Cengage Learning.

Joāo, TF. 2010. The relationship between perceived career mobility, career mobility preference, job satisfaction and organisational commitment. Unpublished master's dissertation, University of South Africa, Pretoria.

Kanwar, YPS, Singh, AK \& Kodwani, AD. 2012. A study of job satisfaction, organisational commitment and turnover intent among the IT and ITES sector employees. The Journal of Business Perspective 16(1):27-35.

Kotze, K \& Roodt, G. 2005. Factors that affect the retention of managerial and specialist staff: An exploratory study of an employee commitment model. SA Journal of Human Resource Management 3(2):48-55.

Lee, TW \& Mitchell, TR. 1994. An alternative approach: The unfolding model of voluntary employee turnover. Academy of Management Review 19:51-89.

Lesabe, RA \& Nkosi, J. 2007. A qualitative exploration of employees' views on organisational commitment. SA Journal of Human Resource Management 5(1): 35-44.

Lev, S \& Koslowsky, M. 2009. Moderating the collective and self-efficacy relationship. Journal of Educational Administration 47(4):452-462.

Lim, GM \& Wong, SF. 2009. Understanding retention of IT professionals in vendor organisations: A job embeddedness model. Journal of Outsourcing and Information Management 1(2):12-17. 
Lumley, EJ. 2009. Exploring the relationship between career anchors, job satisfaction and organisational commitment. Master's dissertation, University of South Africa, Pretoria.

Lumley, EJ, Coetzee, M, Tladinyane, R \& Ferreira, N. 2011. Exploring the job satisfaction and organisational commitment of employees in the information technology environment. Southern African Business Review 15(1):100-118.

Mallol, CM, Holtom, BC \& Lee, TW. 2007. Job embeddedness in a culturally diverse environment. Journal of Business Psychology 22(1):35-44.

Manetje, O \& Martins, N. 2009. The relationship between organisational culture and organisational commitment. Southern African Business Review 13(1):87-111.

March, JG. \& Simon, HA. 1958. Organizations. New York: Wiley.

Maree, K. 2009. First steps in research. Pretoria: Van Schaik.

Martin, SS. 2008. Relational and economic antecedents of organisational commitment. Personnel Review 37(6):589-608.

Martin, A \& Roodt, G. 2008. Perceptions of organisational commitment, job satisfaction and turnover intentions in a post-merger South African tertiary institution. South African Journal of Industrial Psychology 34(1):23-31.

Meyer, JP \& Allen, NJ. 1991. A three-component conceptualization of organizational commitment. Human Resource Management Review 1(1):61-89.

Meyer, JP, Allen, NJ \& Smith, CA. 1993. Commitment to organizations and occupations: Extension and test of a three-component conceptualisation. Journal of Applied Psychology 78(4):538-552.

Meyer, JP \& Herscovitch, L. 2001. Commitment in the workplace toward a general model. Human Resource Management Review 11:299-326.

Miller, D \& Lee, J. 2001. The people make the process: Commitment to employees, decision-making and performance. Journal of Management 27:163-189.

Mitchell, TR, Holtom, BC, Lee, TW, Sablynski, CJ \& Erez, M. 2001a. Why people stay: Using job embeddedness to predict voluntary turnover. Academy of Management Journal 44(6):1102-1121.

Mitchell, TR, Holtom, BC \& Lee, TW. 2001b. How to keep your best employees: Developing an effective retention policy. The Academy of Management Executive 15(4):96-109.

Mohlala, J, Goldman, GA \& Goosen, X. 2012. Employee retention within the Information Technology Division of a South African bank. South African Journal of Human Resource Management 10(2):1-11.

Mowday, RT, Steers, RM \& Porter, LW. 1979. The measurement of organisational commitment. Journal of Vocational Behavior 14(2):224-247.

Müller, SM \& Roodt, G. 1998. The relationship between employees' attitudes towards affirmative action and their work involvement: An explorative study. SA Journal of Industrial Psychology 24(1):26-32.

Muteswa, R \& Ortlepp, K. 2011. Contributing factors to potential turnover in a sample of South African management-level employees. Acta Commercii 11:13-29.

Neuman, WL. 2006. Social research methods: Qualitative and quantitative approaches. Boston: Pearson International. 
Ngobeni, EK \& Bezuidenhout, A. 2011. Engaging employees for improved retention at a higher education institution in South Africa. African Journal of Business Management 5(23):9961-9970.

Nwokocha, I \& Iheriohamma, EB. 2012. Emerging trends in employee retention strategies in a globalizing economy: Nigeria in focus. Asian Social Science 8(10):198-207.

Oates, BJ, Griffiths, G, Lockyer, M \& Hebbron, B. 2004. Empirical methodologies for web engineering. 4th International Conference, 26-30 July, Munich, Germany.

Paré, G \& Tremblay, M. 2007. The influence of high-involvement human resources practices, procedural justice, organisational commitment, and citizenship behaviors on information technology professionals' turnover intentions. Group and Organization Management 32(3):326-357.

Pienaar, C \& Bester, C. 2006. Typical career dilemmas of academic staff during the early career phase within a changing South African higher education institution. South African Journal of Education 26(4):581-594.

Pillay, DL. 2009. Mission attachment as a component of organizational job embeddedness in the trade union sector of South Africa. MBA dissertation, University of Pretoria.

Porter, LW \& Steers, RM. 1973. Organisational, work, and personal factors in employee turnover and absenteeism. Psychological Bulletin 8(2):151-176.

Rabe, M \& Rugunanan, P. 2012. Exploring gender and race amongst female sociologists exiting academia in South Africa. Gender and Education 24(5): 553-566.

Ramesh, A \& Gelfand, MJ. 2010. Will they stay or will they go? The role of job embeddedness in predicting turnover in individualistic and collectivistic cultures. Journal of Applied Psychology 95(5):807-823.

Robbins, SP, Odendaal, A \& Roodt, G. 2003. Organisational behaviour: Global and South African perspectives. Cape Town: Pearson Education.

Rothmann, S \& Jordaan, GME. 2006. Job demands, job resources and work engagement of academic staff in South African higher education institutions. South African Journal of Industrial Psychology 32(4):87-96.

Ryan, JF, Healy, R \& Sullivan, J. 2012. Oh, won't you stay? Predictors of faculty intent to leave a public research university. Higher Education 63:421-437.

Savicki, V, Cooley, E \& Gjesvold, J. 2003. Harassment as predictor of job burnout in correctional officers. Criminal Justice and Behavior 30(5):602-617.

Slocum, JW \& Hellriegel, D. 2007. Fundamentals of organisational behaviour. Mason, $\mathrm{OH}$ : Thomson.

Sutherland, M \& Jordaan, W. 2004. Factors affecting the retention of knowledge workers. South African Journal of Human Resource Management 2(2):55-64.

Tanova, C \& Holtom, BC. 2008. Using job embeddedness factors to explain voluntary turnover in four European countries. The International Journal of Human Resource Management 19(9):1553-1568.

Tettey, WJ. 2010. Challenges of developing and retaining the next generation of academics: Deficits in academic staff capacity at African universities. New York: Partnership for Higher Education in Africa. 
Van Dyk, J. 2011. The relationship between organisational commitment, retention factors and perceived job embeddedness. MCom dissertation, University of South Africa, Pretoria.

Van Dyk, J \& Coetzee, M. 2012. Retention factors in relation to organisational commitment in medical and information technology services. SA Journal of Human Resource Management 10(2), doi.org/10.4102/sajhrm.v10i2.433.

Versfeld, B. 2009. The effect of economic downturn on voluntary labour turnover amongst artisans in South Africa. MBA dissertation, University of Pretoria.

WeiBo, Z, Kaur, S \& Zhi, T. 2010. A critical review of employee turnover model (19382009) and development in perspective of performance. African Journal of Business Management 4(19):4146-4158.

Wheeler, AR, Gallagher, VC, Brouer, RI \& Sablynski, CJ. 2007. When personorganisation (mis)fit and (dis)satisfaction lead to turnover: The moderating role of perceived job mobility. Journal of Managerial Psychology 22(2):203-219.

Yang, C, Ma, Q \& Hu, L. 2011. Job embeddedness: A new perspective to predict voluntary turnover. Nankai Business Review International 2(4):418-446.

Yang, L, Che, H \& Spector, PE. 2008. Job stress and well-being: An examination from the view of person-environment fit. Journal of Occupational and Organizational Psychology 81(3):567-587.

Zhang, M, Fried, DD \& Griffeth, RW. 2012. A review of job embeddedness: Conceptual, measurement issues, and directions for future research. Human Resource management review 22(3):220-31. 